\title{
Simulation Based Comparative Performance Study of AODV, DSR and ZRP in Mobile Ad hoc Networks (MANETs) Using Qualnet 5.0.2
}

\author{
*Suresh Kumar \\ Computer Science \& Engg. Deptt. \\ G.B.Pant Engineering College Pauri \\ GarhwalUttarakhand, INDIA
}

\author{
**Jogendra Kumar \\ Computer Science \& Engg. Deptt \\ G.B.Pant Engineering College Pauri \\ Garhwal Uttarakhand, INDIA
}

\begin{abstract}
A Mobile Ad-Hoc Network (MANET) is a collection of wireless mobile nodes forming a temporary network without using any centralized access point, infrastructure, or centralized administration of the mobile networks .Data transmission between two nodes requires multiple hops as nodes transmission range is limited in Mobile Ad hoc networks (MANET's). Mobility of the networks nodes to makes the situation even more complicated in wireless networks. Multiple routing protocols find optimized routes from a source to some destination. This articles presents performance analysis of three different routing protocols AODV, DSR and ZRP. This article mainly focuses on comparing the performance analysis of three routing protocols for Mobile Ad-Hoc networks (MANET's). We have used QualNet Simulator 5.0.3 from Scalable Networks to perform the simulations. Performance analysis of AODV, DSR and ZRP is evaluated based on Average end to end delay(s), TTL based hop count and Average Jitters(s), throughput (bits/s) in Mobile ad hoc networks.
\end{abstract}

Keywords: AODV, DSR, ZRP, MANET, QualNet 5.0.3 etc.

\section{Introduction}

A mobile ad hoc network (MANET) [1] group has been formed within IETF. The goal is to support mobile ad hoc networks with hundreds of routers and solve challenges. A mobile ad hoc network (MANET) is a self-configuring infrastructure less network of mobile devices connected by wireless links. Each device in a MANET is free to move independently in any direction, and will therefore change its links to other devices frequently. An ad hoc network is a collection of mobile computers or mobile nodes that cooperate to forward packets for each other to extend the limited transmission range of each node's wireless network interface. Each must forward traffic unrelated to its own use, and therefore be a router. Wireless networks are an emerging new technology that will allow users to access information and services electronically, regardless of their geographic position. Wireless networks can be classified in two type's infrastructure network and infrastructure less (ad hoc) networks. Infrastructures network consists of a network with fixed and wired gateways. A mobile host communicates with a bridge in the Network or called base station within its communication radius. The mobile unit can move geographically while it is communicating. When it goes out of range of one base station, it connects with new base station and starts communicating through it. The primary challenge in building a MANET is equipping each device to continuously maintain the information required to properly route traffic. Such networks may operate by themselves or may be connected to the larger Internet. Active research work for mobile ad hoc networks is carrying on mainly in the fields of Medium Access Control (MAC), routing, resource management, power control, and security. Because of the importance of routing protocols in dynamic multi hop networks, a lot of mobile ad hoc network routing protocols have been proposed in the last few years. Mobile ad hoc networks originated from the DARPA (PRNet) [4] and SURAN project [4].

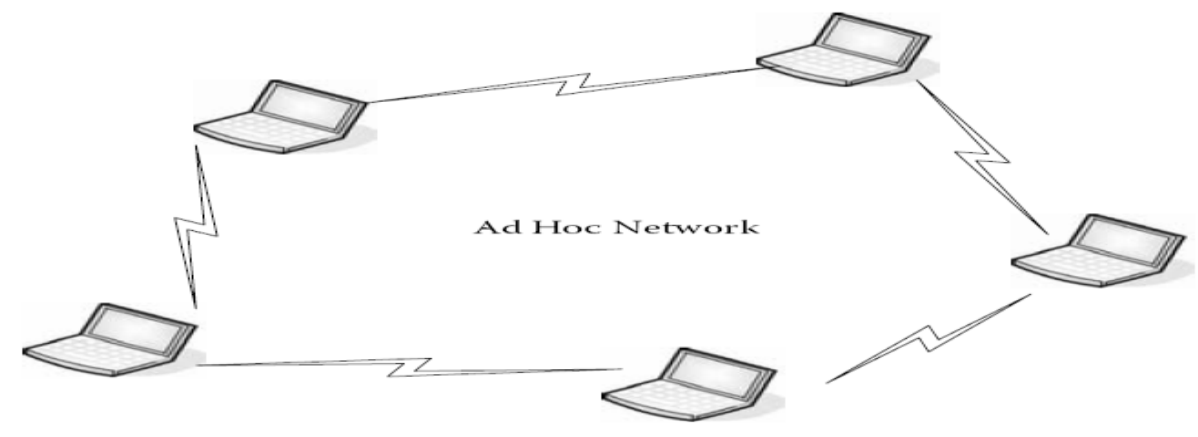

Figure 1 Mobile Ad hoc Networks (MANET) 
IOSR Journal of Engineering

Apr. 2012, Vol. 2(4) pp: 568-572

\section{MOBILE AD HOC NETWORK (MANET)}

A "mobile ad hoc network" (MANET)[1] is an autonomous system of mobile routers and associated hosts connected by wireless links. The routers are free to move randomly and organize themselves arbitrarily; thus, the network's Wireless topology may change rapidly and unpredictably. Such a network may be connected to the larger Internet. Basic Routing functionality for mobile ad hoc networks: A routing protocol is the mechanism by which user Traffic is directed and transported through the network from the source nodes to the destination node.

- Path Generation: generates paths according to the assembled and distributed state information of the network and of the application, assembling and distributing network and user traffic state information.

- Path Selection: selects appropriate paths based on network and application state information

- Data Forwarding: forwards user traffic along the selected route, forwarding user traffic along the selected route

- Path Maintenance: maintaining of the selected route.

\section{Overview of Routing Protocols in Mobile Ad hoc Networks (MANET)}

\section{A. The dynamic source routing (DSR) protocol}

The dynamic source routing protocol (DSR) [2] is an on demand routing protocol. DSR is simple and efficient routing protocol designed specifically for use in multi-hop wireless ad hoc networks of mobile nodes. Using DSR the network is completely self-organizing and self-configuring requiring no existing network infrastructure or administration. The DSR protocol is composed of two main mechanisms that work together to allow the discovery and maintenance of source route in the ad hoc network.

Route discovery is the mechanism by which a node $\mathrm{S}$ wishing to send a packet to a destination node $\mathrm{D}$ obtains a source route to $\mathrm{D}$.Route discovery is used only when $\mathrm{S}$ attempts to sent a packet to $\mathrm{D}$ and does not already know a route to $\mathrm{D}$.

Route maintenance is the mechanism by which node $S$ is able to detect while using a source route to $D$ if the network topology has changed such that it can no longer use it route to $\mathrm{D}$ because a link along the route no longer works. When route maintenance indicates a source route is broken. S can attempts to use any other route it happens to know to $\mathrm{D}$ or it can invoke route discovery again to find a new route for subsequent packets to D. route maintenance for this route is used only when $\mathrm{S}$ is actually sending packets to $\mathrm{D}$.

\section{B. The Ad Hoc On-demand Distance Vector Routing (AODV) protocol}

Reactive routing protocol AODV [3] only needs to maintain the routing information about the active paths. Routing information is maintained in routing tables at nodes. Every mobile node keeps a next-hop routing table, which contains the destinations to which it currently has a route. A routing table entry expires if it has not been used or reactivated for a prespecified expiration time. Moreover, AODV adopts the destination sequence number technique used by DSDV in an on-demand way. In AODV, when a source node wants to send packets to the destination but no route is available, it initiates a route discovery operation. In the route discovery operation, the source broadcasts route request (RREQ) packets. A RREQ includes addresses of the source and the destination, the broadcast ID, which is used as its identifier, the last seen sequence number of the destination as well as the source node's sequence number. Sequence numbers are important to ensure loop-free and up-to-date routes. To reduce the flooding overhead, a node discards RREQs that it has seen before and the expanding ring search algorithm is used in route discovery operation. The RREQ starts with a small TTL (Time-To-Live) value. If the destination is not found, the TTL is increased in following RREQs.

\section{Zone Routing Protocol (ZRP)}

Zone Routing Protocol (ZRP) [4, 6] combines the advantages of both reactive and pro-active protocols into a Hybrid scheme, taking advantage of pro-active discovery within a node's local neighborhood, and using a reactive Protocol for communication between these neighborhoods. In a MANET, it can safely be assumed that the most Communication takes place between nodes close to each other. The ZRP is not so much a distinct protocol as it provides a framework for other protocols. The separation of a nodes local neighborhood from the global topology of the entire network allows for applying different approaches - and thus taking advantage of each technique's features for a given situation. These local neighborhoods are called zones each node may be within multiple overlapping zones, and each zone may be of a different size. The "size" of a zone is not determined by geographical measurement, but is given by a radius of length, where is the number of hops to the perimeter of the zone. By dividing the network into overlapping, variable-size zones, the Zone Routing Protocol consists of several components, which only together provide the full routing benefit to ZRP. Each component works independently of the other and they may use different technologies in order to maximize efficiency in their particular area. Components of ZRP are IARP, IERP and BRP. 


\section{Parameters for Simulation Setup}

\begin{tabular}{|l|l|}
\hline Parameters & Values \\
\hline No of Nodes & 20 \\
\hline Area & $700 \mathrm{~m} * 700 \mathrm{~m}$ \\
\hline Routing Protocols & AODV, DSR and ZRP \\
\hline Fading Model & Rayleigh \\
\hline Shadowing Model & Constant \\
\hline Energy Model & Mica Motes \\
\hline Battery Model & Simple linear \\
\hline Terrain File & DEM \\
\hline Node Placement & Random node placement \\
\hline Simulation time & 120 sec \\
\hline Channel frequency & $2.4 \mathrm{Ghz}$ \\
\hline Traffic Source & CBR \\
\hline
\end{tabular}

Tables1. Parameters for simulation setup scenarios

\section{Nodes Placement Scenarios}

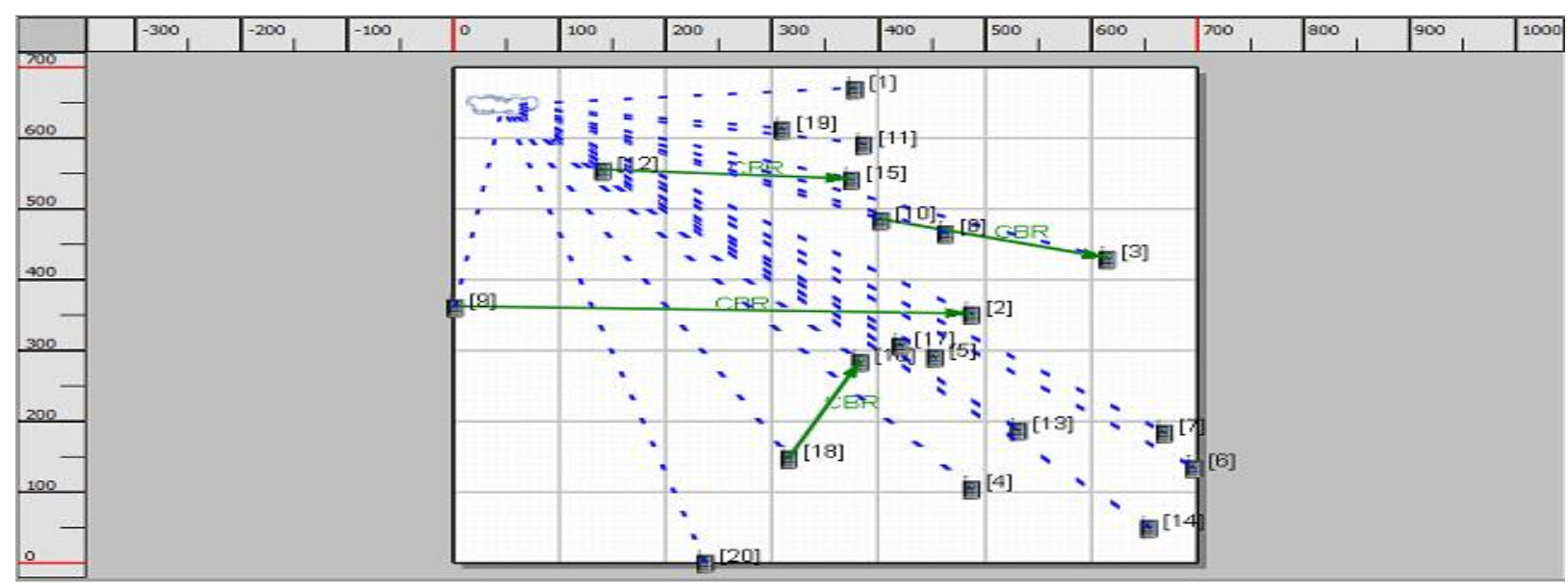

Figure 2 Nodes placement scenarios for AODV, DSR and ZRP R outing Protocol

\section{Animation View of Scenarios}

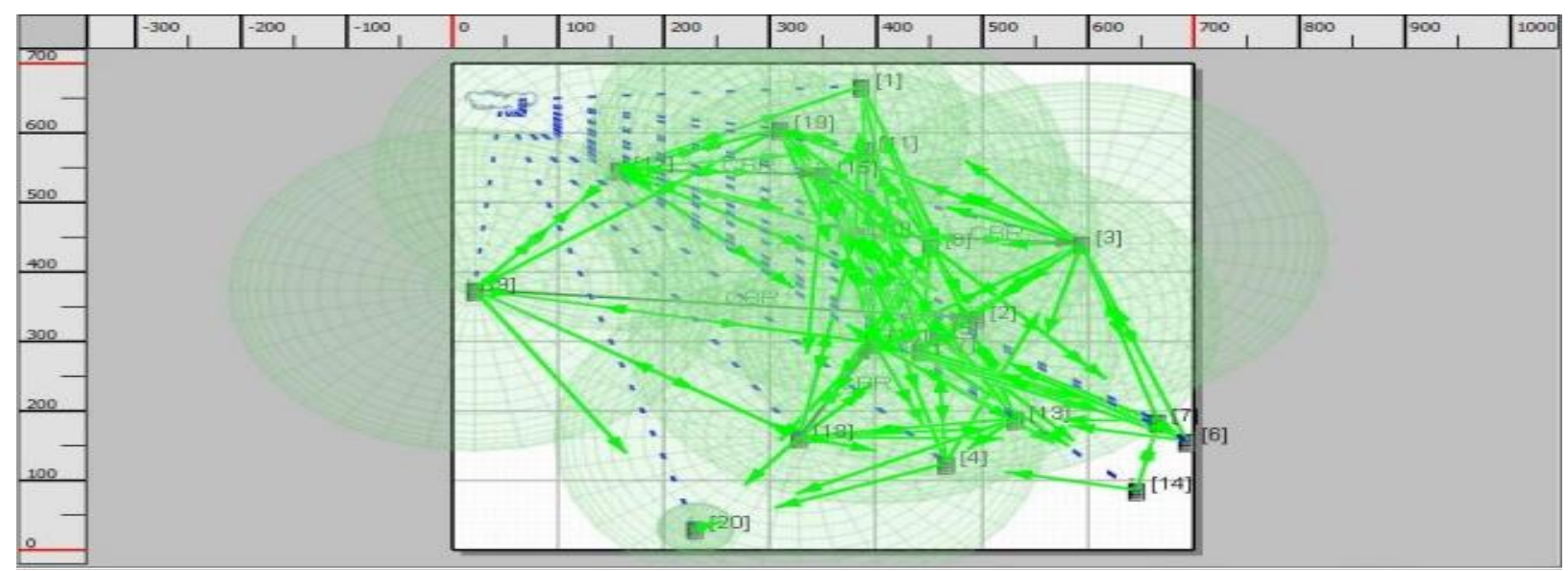

Figure 3 Animation View of scenarios for AODV, DSR and ZRP R outing Protocol 
IOSR Journal of Engineering

Apr. 2012, Vol. 2(4) pp: 568-572

\section{Simulation results of AODV, DSR and ZRP Protocols on 20 Nodes}

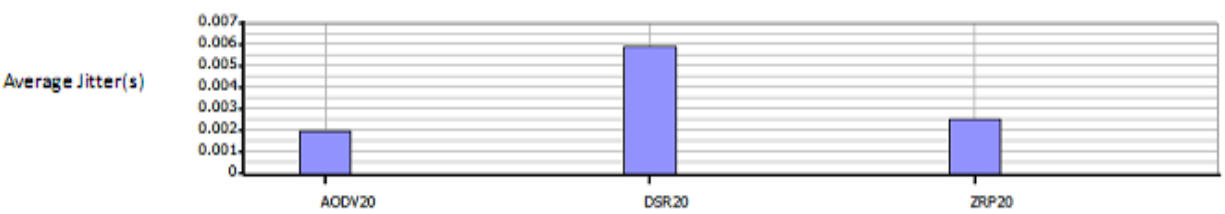

Figure4. Average Jitter(s) Vs Nodes of Routing Protocols

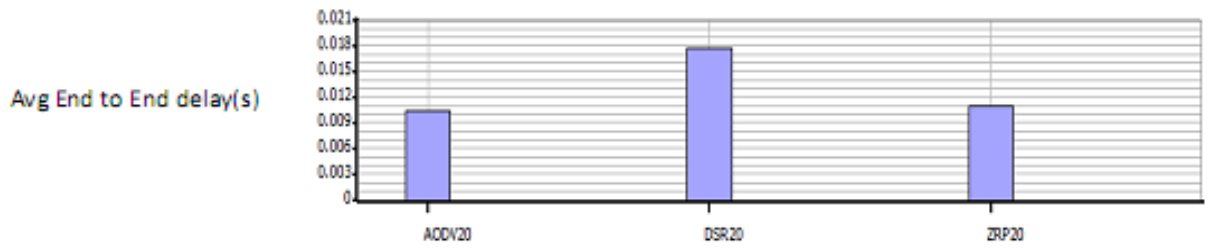

Figure5. Average End to End delay(s) Vs Nodes of Routing Protocols

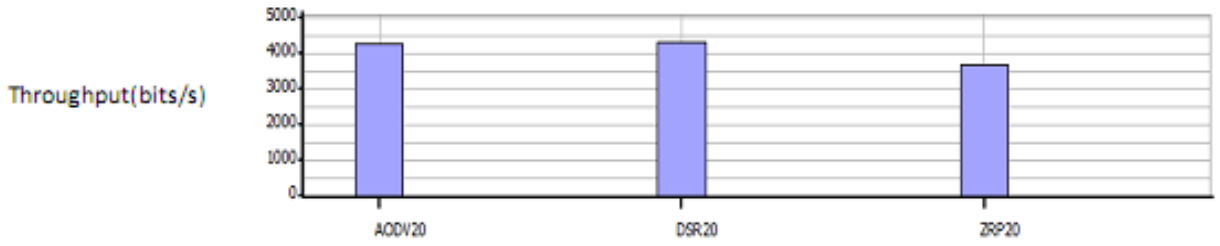

Figure 6.Throughput (bits/s) Vs Nodes of Routing Protocols

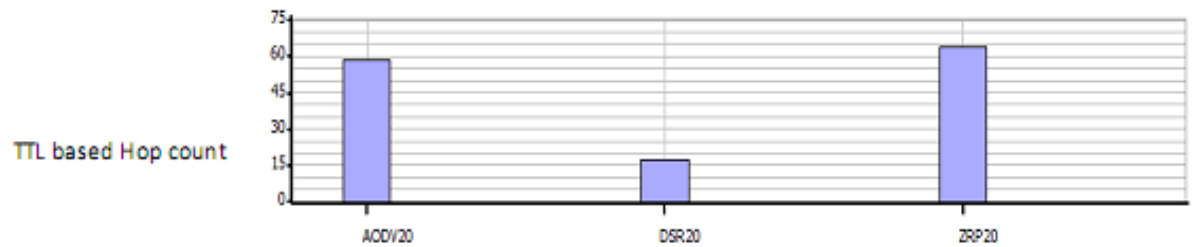

Figure 7.TTL based Hop count Vs Nodes of Routing Protocols

\section{ACKNOWLEDGEMENT}

Jogendra kumar thanks Mr. Sandipvijay Head of the Department (HOD) and Professor of Electronic Communination \& Engineering in DIT (Dehradun Institute of Technology) Uttarakhand by recognized UTU (Uttarakhand Technology University) Dehradun, Uttarakhand ,INDIA and also Thanks HOD CSED G.B.Pant Engineering College Pauri Garhwal Uttarakhand ,INDIA give me opportunity and provided simulation tools Qualnet 5.0.2 to complete this article on Simulation Based Comparative Study of AODV, DSR and ZRP in Mobile Ad hoc Networks (MANETs) Using Qualnet 5.0.2.

\section{Conclusion:}

In this article we have provided descriptions of three routing protocols for mobile ad hoc networks. In this article mainly focus on proactive, reactive, and hybrids routing protocols like AODV ,DSR, and ZRP .we have analysis performance of these routing protocols on the basis of Performance Matrices Average End to End delay(s),throughput (bits/s),Average Jitters(s) and TTL based Hop count. These performances taken according to apply constant bit rate (CBR) of nodes from source to destination. All CBR starting time $1 \mathrm{sec}$ from source and $25 \mathrm{sec}$ end from the destination nodes of CBR All simulation time of the scenarios $120 \mathrm{sec}$ to complete of the process. 


\section{AUTHOR'S PROFILE}

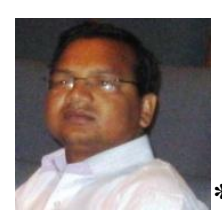

*Suresh Kumar is working as an Assistant Professor in Department of Master Computer Application (MCA) at G.B.Pant Engineering College Pauri Garhwal, Uttarakhand, India. His area of interest includes Sensor network, ad hoc network, image processing and also published various research papers in leading journal \& conferences.

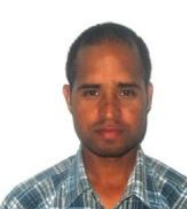

4. **Jogendra Kumar received his B.E. degree in Computer Science \& Engineering from H.N.B Garhwal University Srinagar Uttarakhand (India) in G.B. Pant Engineering College Pauri Garhwal, Uttarakhand, (India) 2008 and he is currently doing M.Tech (CSE) degree from UTU University Dehradun Uttarakhand (India) in G.B. Pant Engineering College Pauri Garhwal, Uttarakhand, (India) with Registration ID No CSE1053545. His research interest includes mobile ad hoc networks and wireless sensor networks systems.

\section{References}

[1] C.Siva Rammurty and B.S.Manoj [2011],"Ad hoc wireless networks architectures and protocols".

[2] Subir kumar sarkar T G Basavaraju C Puttamadappa [2008],"Ad hoc Mobile Wireless Networks Principles, Protocols and Applications"

[3] Dr.Brijesh Gupta [2008]"Mobile Computing Technology, Applications, issues and research directions"

[4] John Jubin and Janet D.Tornow[January 1987], the DARPA Packet Radio Network Protocols." Proceedings of the IEEE", 75(1):21-32.

[5] The Qualnet (5.0.3) simulator www.scalable-networks.com.

[6] S. Murthy and J.J. Garcia-Luna-Aceves [Oct. 1996] "An Efficient Routing Protocol for Wireless Networks", ACM Mobile Networks and App. J., Special Issue on Routing in Mobile Communication Networks, pp. 183-97 